$\begin{array}{cc}\text { ACADEMIA ROMÂNĂ } & \text { Rev. Roum. Chim., } \\ \text { 2020, 65(4), 375-385 }\end{array}$

\title{
SIMULTANEOUS DETERMINATION OF QUERCETIN AND LUTEOLIN IN MATE AND WHITE TEA SAMPLES BY VOLTAMMETRY
}

\author{
Kuddusi KARABODUK ${ }^{\mathrm{a}, *}$ and Erdoğan HASDEMIR ${ }^{\mathrm{b}}$ \\ ${ }^{a}$ Life Sciences Application and Research Center, Gazi University, 06830, Golbasi, Ankara, Turkey \\ ${ }^{b}$ Faculty of Sciences, Department of Chemistry, Gazi University, 06500, Besevler, Ankara, Turkey
}

The chemical structures of quercetin and luteolin are quite similar; as a result, their oxidation peaks potential are close and interfere each other. To solve this problem, in this study, the simultaneous determination method of quercetin and luteolin has been developed on glassy carbon electrode (GCE) by using differential pulse voltammetry (DPV). $75 \%$ methanol (hydro-alcoholic) support electrolyte was used for this purpose. The peak potential difference between the quercetin and luteolin was at about $110 \mathrm{mV}$ which was useful for the simultaneous electrochemical analysis of both species. The experimental parameters were optimized. Under optimized conditions, linearity was obtained in the ranges of $0.079-39.60 \times 10^{-7} \mathrm{M}$ and $39.60-148.50$ $\times 10^{-7} \mathrm{M}$ for quercetin, and $0.065-32.60 \times 10^{-7} \mathrm{M}$ and $32.60-122.50 \times 10^{-7}$ for luteolin. The detection limits for quercetin and luteolin were $0.022 \times 10^{-7} \mathrm{M}$ and $0.018 \times 10^{-7} \mathrm{M}$, respectively. Finally, the present method was employed for the simultaneous determination of quercetin and luteolin in the ethanol and methanol extracts of Mate and White tea samples, and the obtained results were verified by high performance liquid chromatography as a

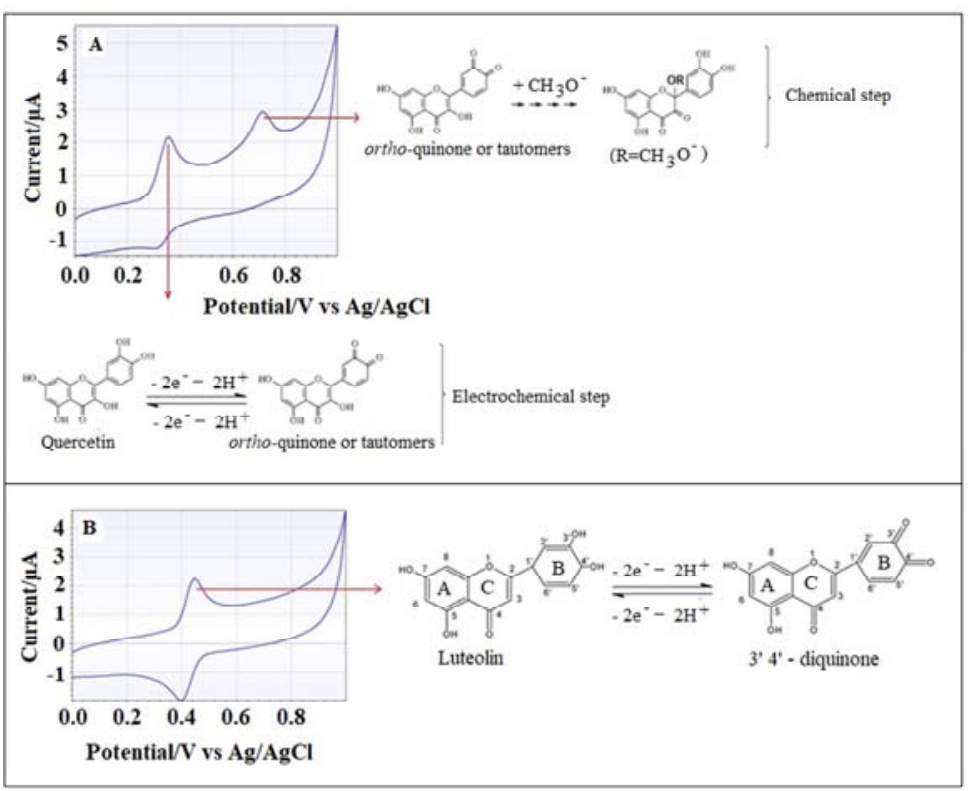
confirmatory method.

\section{INTRODUCTION}

Quercetin (Qu) (3,5,7,3',4'-pentahydroxyflavone) is a member of polyphenol. It is one of the most common flavonoids in the daily diet. Quercetin is known as an effective antioxidant ingredient and possesses different bioactive effects such as anticancer, anti-inflammatory activities and pre- vention of retinal degeneration. ${ }^{1-4}$ Luteolin (Lu) $\left(3^{\prime}, 4^{\prime}, 5,7\right.$-tetra- hydroxyflavone) is one of the most abundant occurring flavonoids in variety of vegetables, spices, and medical plants. Luteolin has several pharmacological benefits, such as anticancer, anti-inflammatory, antioxidant and antiviral effects. ${ }^{5,6}$ Also, Kwon (2017) reported that for neurodegenerative diseases preventive

*Corresponding author: kuddusi@gazi.edu.tr 
treatment of luteolin might have a positive effect due to its anti-inflammatory activity and other biological functions including antioxidant activity. ${ }^{7}$

Because of $\mathrm{Qu}$ and $\mathrm{Lu}$ have beneficial effects for human health; the determination of these flavonoids has been an interesting research area for a long time. Various analytical methods have been developed for the determination of $\mathrm{Qu}$ and $\mathrm{Lu}$, such as HPLC-UV, HPLC-DAD, HPLC-QTOF-MS, HPLC-DADESI/MS, UFLC-MS/MS, capillary electrophoresis, isocratic LC-DAD-FLD. ${ }^{8-15}$ These methods may be highly selective but they require expensive and complex equipment, time for analysis and excessive use of chemicals. Voltammetric techniques and equipment are suitable for fieldwork, because they do not require ponderous items and electroanalytical techniques are low cost and they offer easy operation, high simplicity and short analysis time. Recently, some electrochemical determination methods and electrodes have been developed for $\mathrm{Qu}$ and $\mathrm{Lu}^{16-25}$ Oxidation peaks of $\mathrm{Qu}$ and $\mathrm{Lu}$ are overlapped because of their similar structure. Thus, it is very difficult to simultaneous determination of $\mathrm{Qu}$ and $\mathrm{Lu}$. In the literature, there was only one study about the simultaneous electrochemical determination of $\mathrm{Qu}$ and $\mathrm{Lu}^{26}$ Chamizo-Gonzalez, Monago-Marana and Galeano-Diaz (2017) reported DPV and partial least squares.

$\mathrm{Qu}$ and $\mathrm{Lu}$ are the most common flavonoids in plants, because of this, co-evaluation of them is very important. The aim of this study is to develop a simple and sensitive DPV method for the simultaneous determination of $\mathrm{Qu}$ and $\mathrm{Lu}$, for this reason, hydro-alcohol support electrolyte $(75 \%$ methanol) and non-modified GCE were used for the simultaneous determination of both analytes. $\mathrm{Qu}$ and $\mathrm{Lu}$ have been determinated successfully in Mate and White tea extract.

\section{RESULTS AND DISCUSSION}

\section{Electrochemical behaviors of Quercetin and Luteolin}

Electrochemical behaviors of $\mathrm{Qu}$ and $\mathrm{Lu}$ were evaluated by $\mathrm{CV}$. Figure $1 \mathrm{~A}$ shows the $\mathrm{CV}$ curves at GCE for increasing amounts of $\mathrm{Qu}$ in $\mathrm{pH} 5$ phosphate buffer $(0.1 \mathrm{M})$. Quercetin had two oxidation peaks and these peaks were clearly seen at $+0.32 \mathrm{~V}$ and $+0.72 \mathrm{~V}$. The oxidation peaks of $\mathrm{Qu}$ were rather broad, which indicates a slow electron transfer kinetics. When Lu was added, the rather broad oxidation peak $(+0.41 \mathrm{~V})$ of $\mathrm{Lu}$ overlapped with the oxidation peak of $\mathrm{Qu}$ at $+0.32 \mathrm{~V}$ and the $\mathrm{Qu}$ oxidation peak at $+0.72 \mathrm{~V}$ decreased and disappeared. Figure 1B shows the $\mathrm{CV}$ curves of different concentration of $\mathrm{Lu}$ in $\mathrm{pH} 5$ phosphate buffer $(0.1 \mathrm{M})$. The oxidation peak of $\mathrm{Lu}$ appeared at $+0.41 \mathrm{~V}$. By addition of $\mathrm{Qu}$ to the support electrolyte, the oxidation peaks of $\mathrm{Lu}$ and $\mathrm{Qu}$ were overlapped and voltammogram did not show specific peaks for each analyte, making difficult to construct individual calibration curves.

When the electrochemical behaviors of $\mathrm{Qu}$ and $\mathrm{Lu}$ at different $\mathrm{pH}$ values were examined, similar electrochemical behaviors were observed at $\mathrm{pH} 2$ for $\mathrm{Qu}$ and $\mathrm{Lu}$. The increasing of $\mathrm{pH}$ caused the shift of anodic peak potentials of $\mathrm{Qu}$ and $\mathrm{Lu}$ towards the less positive potential side and these peaks overlapped (Figure 2). Because, at $\mathrm{pH} 2$ and $\mathrm{pH}$, hydroxyl groups of $\mathrm{Qu}$ and $\mathrm{Lu}$ were active along with catechol hydroxyl group. ${ }^{16}$

However, there is still the overlap problem. To overcome this problem, hydro-alcoholic support electrolyte was used. In $\mathrm{pH} 5$ phosphate buffer (0.1 M, 75\% methanol), well discriminated oxidation peaks were obtained for both species as shown in Figure 3. Two oxidation peaks of quercetin were obtained distinctly. The oxidation peaks of $\mathrm{Qu}$ became more accentuated with methanol, while the addition of Lu did not affect the oxidation peak of $\mathrm{Qu}$. This result showed that the methanolic medium was suitable for both analyte determinations.

The electrochemical oxidation of quercetin was related with the groups of catechol in B ring and the three hydroxyl groups of $\mathrm{A}$ and $\mathrm{C}$ rings (Figure 4A). Firstly, the two-OH catechol groups of quercetin $\mathrm{B}$ ring were oxidized at low positive potentials and two electrons and protons were transferred. ${ }^{27}$ In this experimental conditions, quercetin showed two oxidation peaks at $+0.319 \mathrm{~V}$ and $+0.660 \mathrm{~V}$, respectively. This result was similar to that of Timbola et al. (2006). ${ }^{28}$ Timbola et al. (2006) studied in ethanolic medium and explained two oxidation peaks of quercetin. In $\mathrm{pH} 5$ phosphate buffer $(0.1 \mathrm{M}, 75 \%$ methanol), luteolin had one oxidation peak at $+0.429 \mathrm{~V}$. Figure 4A. shows the suggestion of Qu oxidation processes. In the first step, which is electrochemical step, quercetin oxidizes to electroactive ortho-quinone or tautomers with electrochemically and in the chemical step, ring $\mathrm{C}$ deprotonates. In this study, first oxidation peak at $+0.319 \mathrm{~V}$ was used for the determination of quercetin. 


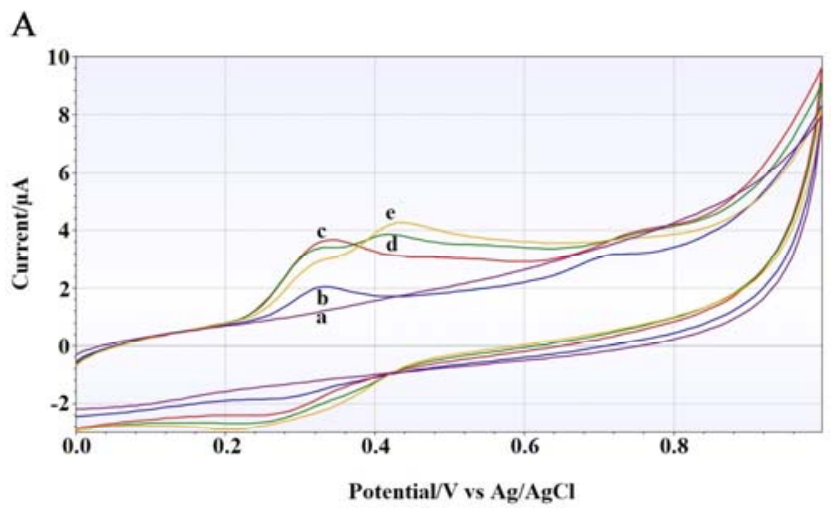

B

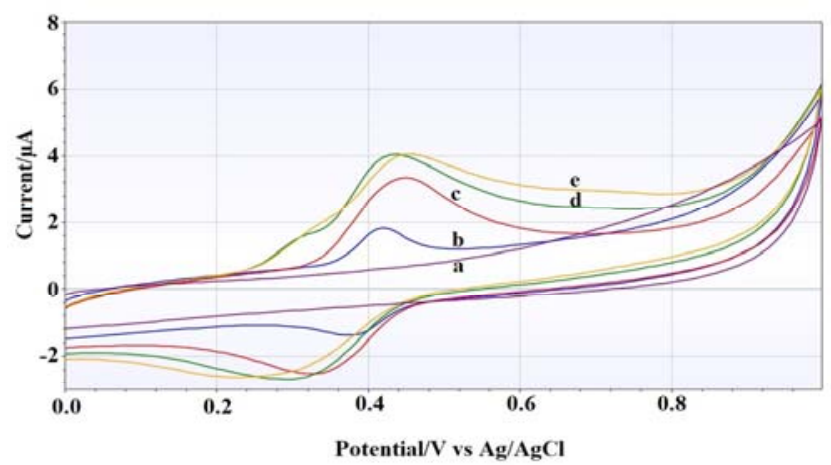

Fig. 1 - (A) Cyclic voltammograms of Qu (b: $1.92 \times 10^{-6} \mathrm{M}$, c: $\left.3.82 \times 10^{-6} \mathrm{M}\right)$ and Qu $\left(3.82 \times 10^{-6} \mathrm{M}\right)+\mathrm{Lu}\left(\mathrm{d}: 1.92 \times 10^{-6} \mathrm{M}\right.$, e: $\left.3.82 \times 10^{-6} \mathrm{M}\right)$ in pH 5 phosphate buffer $(0.1 \mathrm{M})$; (B) Cyclic voltammograms of $\mathrm{Lu}\left(\mathrm{b}: 1.92 \times 10^{-6} \mathrm{M}\right.$, c: $\left.3.82 \times 10^{-6} \mathrm{M}\right)$ and $\mathrm{Lu}\left(3.82 \times 10^{-6} \mathrm{M}\right)+\mathrm{Qu}$ (d: $1.92 \times 10^{-6} \mathrm{M}$, e: $\left.3.82 \times 10^{-6} \mathrm{M}\right)$ in $\mathrm{pH} 5$ phosphate buffer $(0.1 \mathrm{M})$; a: support electrolyte, scan rate: $100 \mathrm{mV} / \mathrm{s}$.

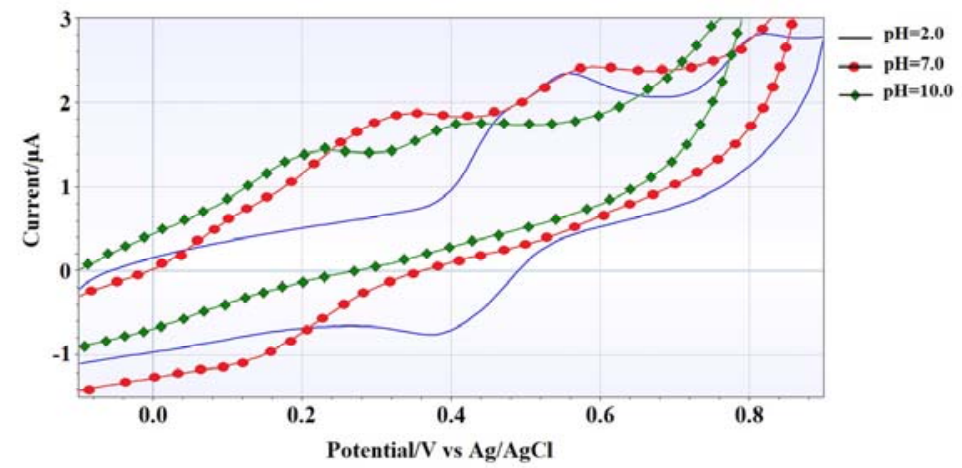

Fig. 2 - Cyclic voltammograms for $1.92 \times 10^{-6} \mathrm{M} \mathrm{Qu}$ and $\mathrm{Lu}$ on GCE at different $\mathrm{pH}(\mathrm{pH} 2, \mathrm{pH} 7$ and $\mathrm{pH} 10)$; scan rate: $100 \mathrm{mV} / \mathrm{s}$.

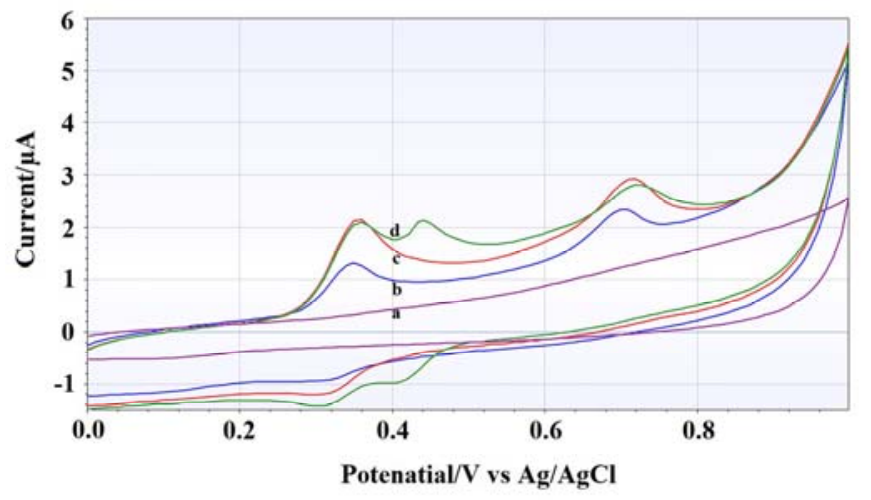

Fig. 3 - Cyclic voltammograms of Qu (b: $1.92 \times 10^{-6} \mathrm{M}$, c: $\left.3.82 \times 10^{-6} \mathrm{M}\right)$ and $\mathrm{Qu}\left(3.82 \times 10^{-6} \mathrm{M}\right)+\mathrm{Lu}\left(1.92 \times 10^{-6} \mathrm{M}\right)(\mathrm{d})$ in $\mathrm{pH} 5$ phosphate buffer, support electrolyte (pH 5 phosphate buffer $(0.1 \mathrm{M}, 75 \%$ methanol) (a). 


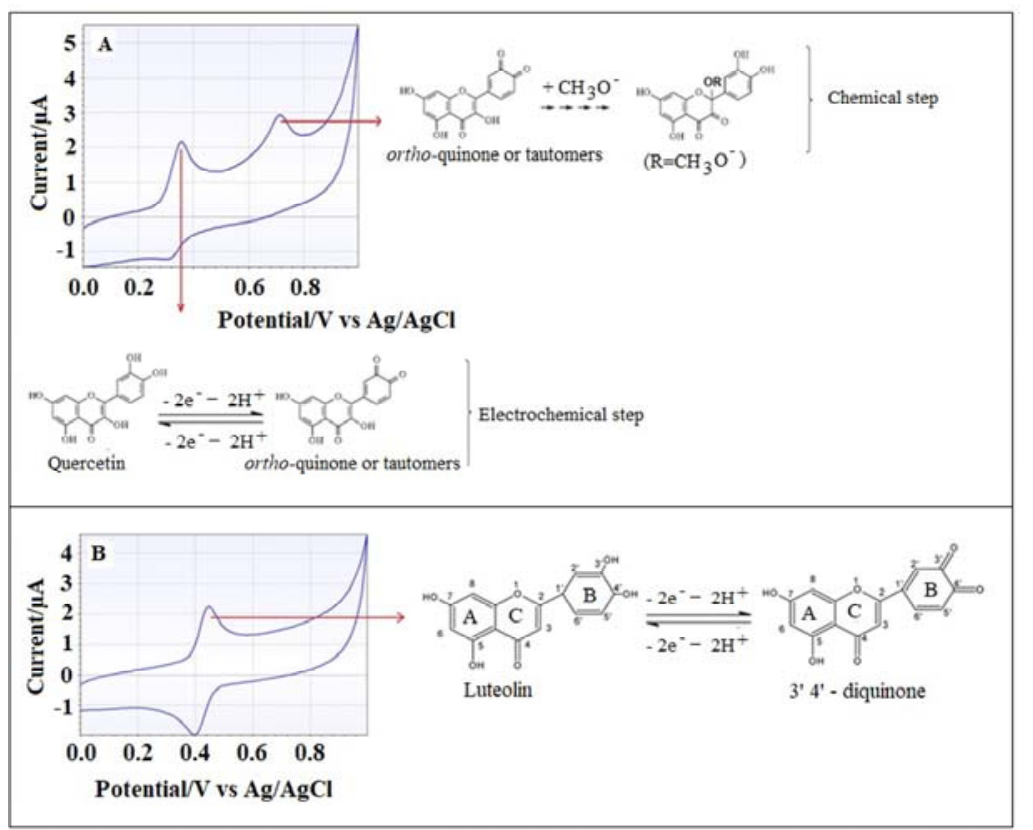

Fig. 4 - Cyclic voltammograms and oxidation reactions of quercetin (A) and luteolin (B), in pH 5 phosphate buffer $(0.1 \mathrm{M}, 75 \%$ methanol $)$ at GCE, concentrations of quercetin and luteolin: $1.92 \times 10^{-6} \mathrm{M}$, scan rate: $175 \mathrm{mV} / \mathrm{s}$.

The electrooxidation mechanism of luteolin was involved in losing two protons and two electrons to give the final product of 3' 4'-diquinone. ${ }^{29} \mathrm{~A}$ single oxidation peak was at over $+0.429 \mathrm{~V}$ (Figure 4B).

\section{Effect of co-solvent and amount of co-solvent}

Ghasemzadeh, Jaafar and Rahmat (2011) reported the methanol has better characteristics as a solvent for phenolic compounds and flavonoids than ethanol, acetone and chloroform because of its high polarity. ${ }^{30}$ Therefore, aqueous methanol supporting electrolyte was chosen for simultaneous determination of $\mathrm{Qu}$ and $\mathrm{Lu}$. The influence of methanol ratio to $\mathrm{Qu}$ and $\mathrm{Lu}$ oxidation peak separations and peak current values were studied and this parameter was evaluated at $\mathrm{pH} 5$ phosphate buffer (\% methanol: $25 \% \rightarrow 75 \%$ ). When methanol ratio in support electrolyte was decreased, the electrochemical behaviors of $\mathrm{Qu}$ and $\mathrm{Lu}$ became similar to the behaviors of nonmethanol medium. With the aim of securing the separation and current value of peaks, and support electrolyte features, $75 \%$ methanol was selected for the current study.

\section{Effect of pH}

The electrochemical behaviors of $\mathrm{Qu}$ and $\mathrm{Lu}$ at glassy carbon electrode were affected with the $\mathrm{pH}$ of support electrolyte (Table 1). The peak potentials of oxidation were shifted through less potential with the increase of $\mathrm{pH}$ value, which was about protons' participation in the electrochemical oxidation processes of $\mathrm{Qu}$ and $\mathrm{Lu} .{ }^{18}$ From $\mathrm{pH} 2$ to $\mathrm{pH} 12$, the highest oxidation current values were obtained at $\mathrm{pH} 5$ phosphate buffer ( $75 \%$ methanol) by $\mathrm{CV}$. The oxidation peak current values of $\mathrm{Qu}$ and $\mathrm{Lu}$ were closed at $\mathrm{pH} 2$ and $\mathrm{pH} 5$, but the electrochemical oxidation of $\mathrm{Qu}$ and $\mathrm{Lu}$ at $\mathrm{pH} 5$ showed less potential than $\mathrm{pH}$ 2. $\mathrm{pH} 5(75 \%$ methanol) was chosen for the simultaneous determination of $\mathrm{Qu}$ and $\mathrm{Lu}$.

\section{Effect of scan rate}

Figure 5 shows the cyclic voltammograms of $1.92 \times 10^{-6} \mathrm{M}$ Qu and $\mathrm{Lu}$ in $\mathrm{pH} 5$ phosphate buffer (0.1 M, 75\% methanol) with scan rates ranging from 25 to $225 \mathrm{mV} / \mathrm{s}$ at GCE. The oxidation peak currents of $\mathrm{Qu}$ and Lu gradually increased when increasing the scan rate from 25 to $175 \mathrm{mV} / \mathrm{s}$. The linear regression equations of $\mathrm{Qu}$ and $\mathrm{Lu}$ were expressed as;

and

$$
I_{p}=1.182 v-0.848\left(\mathrm{R}^{2}=0.9994\right)
$$

$$
I_{p}=1.275 v-0.740\left(\mathrm{R}^{2}=0.9938\right)
$$

respectively, which suggest that the redox process of both analytes at GCE was an adsorptioncontrolled process. 
Table 1

Effect of $\mathrm{pH}$ on oxidation peaks potential and current value, each analyte: $1.92 \times 10^{-6} \mathrm{M}$ (methanol: $75 \%$ )

\begin{tabular}{|c|c|c|c|c|c|c|c|c|}
\hline \multirow[b]{2}{*}{ Analyte } & \multicolumn{2}{|c|}{ pH 2} & \multicolumn{2}{|c|}{ pH 5} & \multicolumn{2}{|c|}{ pH 7} & \multicolumn{2}{|c|}{ pH 12} \\
\hline & $\begin{array}{c}E_{p} \\
(\mathrm{mV})\end{array}$ & $\begin{array}{c}I p \\
(\mu \mathrm{A})\end{array}$ & $\begin{array}{c}E_{p} \\
(\mathrm{mV})\end{array}$ & $\begin{array}{c}I p \\
(\mu \mathrm{A})\end{array}$ & $\begin{array}{c}E_{p} \\
(\mathrm{mV})\end{array}$ & $\begin{array}{c}I p \\
(\mu \mathrm{A})\end{array}$ & $\begin{array}{c}E_{p} \\
(\mathrm{mV})\end{array}$ & $\begin{array}{c}I p \\
(\mu \mathrm{A})\end{array}$ \\
\hline Quercetin & 529 & 1.34 & 319 & 1.38 & 139 & 1.20 & -190 & 0.42 \\
\hline Luteolin & 619 & 1.43 & 429 & 1.48 & 269 & 0.97 & 99 & 0.17 \\
\hline
\end{tabular}

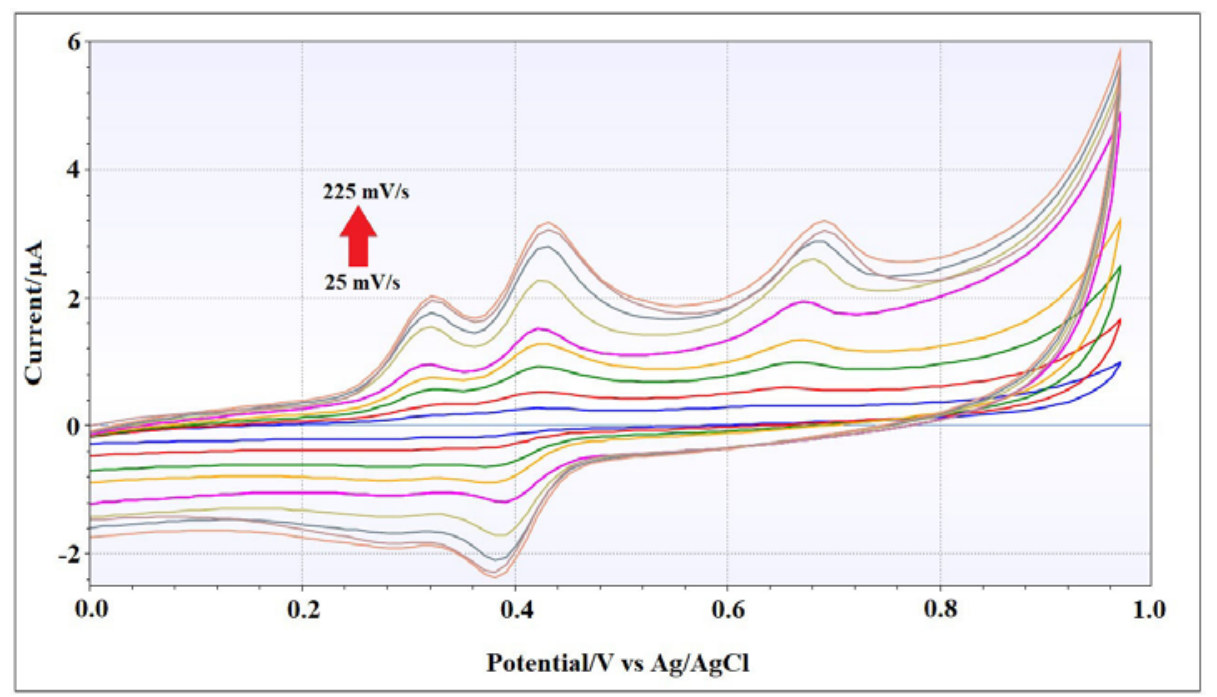

Fig. 5 - CV voltammograms of Qu and Lu with different scan rate at GCE in $\mathrm{pH} 5$ phosphate buffer ( $0.1 \mathrm{M}, 75 \%$ methanol). The scan rates were as follows: $25,50,75,100,125,150,175,200,225 \mathrm{mV} / \mathrm{s}$, each analyte concentration: $1.92 \times 10^{-6} \mathrm{M}$.

It can be seen from Figure 5 that the oxidation peak currents of $\mathrm{Qu}$ and $\mathrm{Lu}$ increased with an increase of scan rate until it reached $175 \mathrm{mV} / \mathrm{s}$; therefore, $175 \mathrm{mv} / \mathrm{s}$ of scan rate was selected as the optimum scan rate in the subsequent process.

\section{Selective determinations of $\mathrm{Qu}$ and $\mathrm{Lu}$ in the presence of fixed concentrations of $\mathrm{Lu}$ and $\mathrm{Qu}$}

Figure 6A shows the differential puls voltammogram obtained from the different concentrations of $\mathrm{Lu}$ in the presence of $2.49 \times 10^{-7}$ $\mathrm{M} \mathrm{Qu}$. The oxidation peaks did not shift during the addition of $\mathrm{Lu}$. The oxidation peak current of $\mathrm{Lu}$ was increased linearly $\left(\mathrm{R}^{2}: 0.9976\right.$ and the linear regression equation: $I_{p}=0.4153 \mathrm{C}+0.5808$ ).

Similarly, the oxidation peak of $\mathrm{Qu}$ was evaluated at the fixed concentration of $\mathrm{Lu}$. As shown in Figure 6B, the oxidation potential of $\mathrm{Qu}$ did not shift to any potential and the peak current value increased linearly with the increasing concentration of $\mathrm{Qu}\left(\mathrm{R}^{2}=0.9982\right.$ and the linear regression equation: $I p=0.3633 \mathrm{C}+1.2212)$. In all of the studies, the voltammetric peak currents of fixed species remained the same.

\section{Analytical application}

Two well-separated oxidation peaks at about $+0.319 \mathrm{~V}$ and $+0.429 \mathrm{~V}$ were obtained for simultaneous determination of $\mathrm{Qu}$ and $\mathrm{Lu}$, respectively. The peak current was linearly proportional to the concentration of $\mathrm{Qu}$ ranging from 0.0792 to $39.60 \times 10^{-7} \mathrm{M}$ and 39.60 to 148.50 $\times 10^{-7} \mathrm{M}$ (the first linear regression equation: $I p_{1}=$ $4.5235 \mathrm{C}-0.7364\left(\mathrm{R}^{2}=0.9994\right)$ with a sensitivity of $63.71 \mu \mathrm{A} \mu \mathrm{M}^{-1} \mathrm{~cm}^{-2}$ and the second linear regression equation: $I p_{2}=2.2126 \mathrm{C}+91.732\left(\mathrm{R}^{2}=\right.$ $0.9989)$ with a sensitivity of $31.16 \mu \mathrm{A} \mu \mathrm{M}^{-1} \mathrm{~cm}^{-2}$ ) and, the calibration plot displayed a good linear relationship between the peak currents and the concentrations of $\mathrm{Lu}$ in the range from 0.0652 to 
$32.60 \times 10^{-7} \mathrm{M}$ and 32.60 to $122.50 \times 10^{-7} \mathrm{M}$ (the first linear regression equation: $I p_{1}=6.3996 \mathrm{C}+$ $1.3851\left(\mathrm{R}^{2}=0.9989\right)$ with a sensitivity of 91.13 $\mu \mathrm{A} \mu \mathrm{M}^{-1} \mathrm{~cm}^{-2}$ and the second linear regression equation: $I p_{2}=3.7447 \mathrm{C}+84.087\left(\mathrm{R}^{2}=0.9996\right)$ with a sensitivity of $52.74 \mu \mathrm{A} \mu \mathrm{M}^{-1} \mathrm{~cm}^{-2}$ ) (Figure 7A - 7C). Two slopes were observed. The reason for these two different regions was that high concentrations of $\mathrm{Qu}$ and $\mathrm{Lu}$ caused saturation in the interface and less signals at the current value. ${ }^{31}$

The detection limits were estimated to be 0.0220 $\times 10^{-7} \mathrm{M}(\mathrm{S} / \mathrm{N}=3)$ for $\mathrm{Qu}$ and $0.0182 \times 10^{-7} \mathrm{M}$ $(\mathrm{S} / \mathrm{N}=3)$ for $\mathrm{Lu}$, which were comparable with the values reported by the other researchers (Table 2).

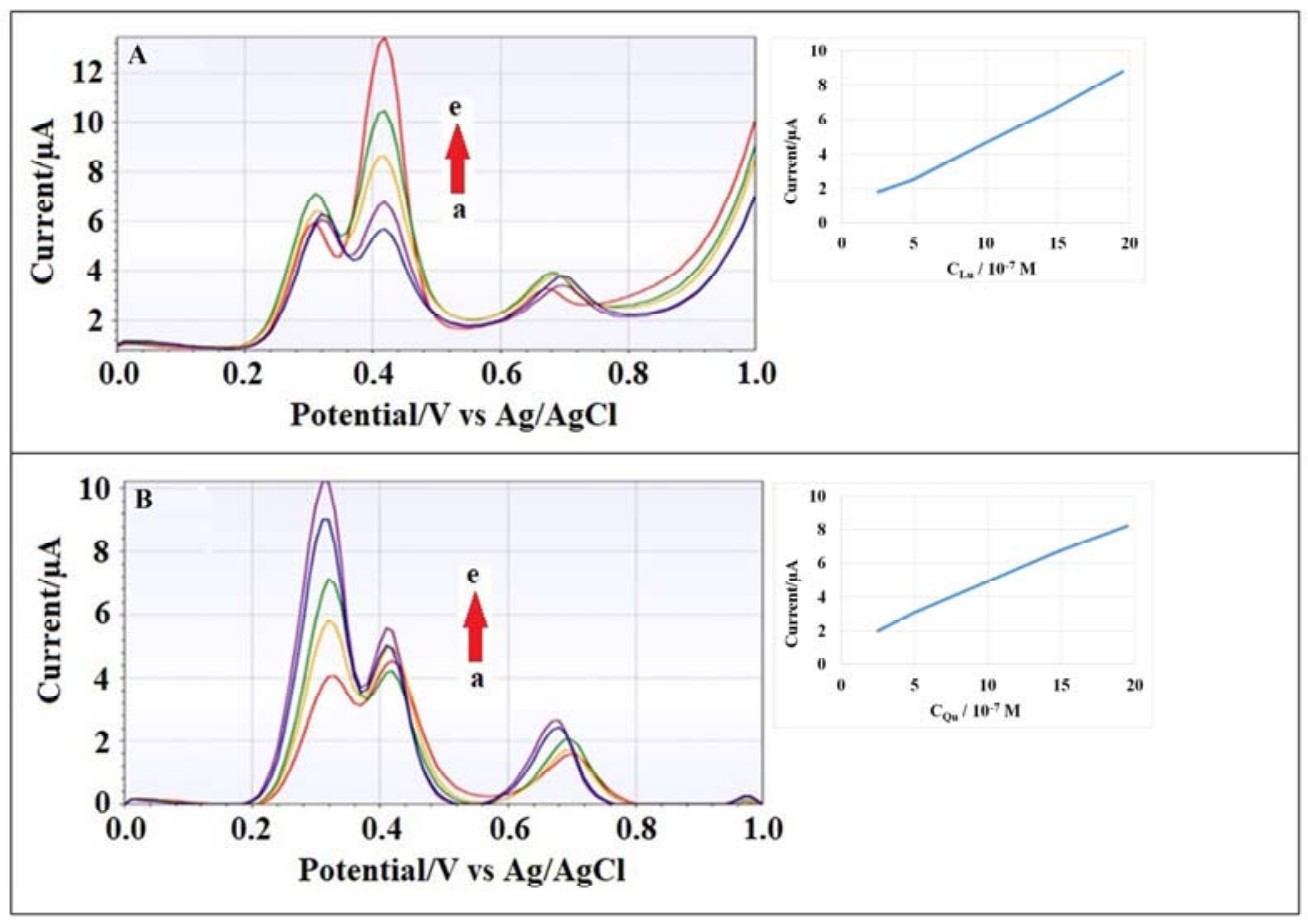

Fig. 6 - (A) Differential puls voltammograms of $\mathrm{Lu}$ in the presence of $2.49 \times 10^{-7} \mathrm{M}$ Qu at GCE in pH 5 phosphate buffer $(0.1 \mathrm{M}, 75 \%$ methanol), Lu concentration range $(\mathrm{a} \rightarrow \mathrm{e}): 2.49 \times 10^{-7}, 4.95 \times 10^{-7}, 9.95 \times 10^{-7}, 14.70 \times 10^{-7}, 19.51 \times 10^{-7} \mathrm{M}$; (B) differential puls voltammograms of Qu in the presence of $2.49 \times 10^{-7} \mathrm{M} \mathrm{Lu}$ at GCE in pH 5 phosphate buffer $(0.1 \mathrm{M}, 75 \%$ methanol), Qu concentration range $(\mathrm{a} \rightarrow \mathrm{e}): 2.49 \times 10^{-7}, 4.95 \times 10^{-7}, 9.95 \times 10^{-7}, 14.70 \times 10^{-7}, 19.51 \times 10^{-7} \mathrm{M}$. Pulse amplitude: $50 \mathrm{mV}$, pulse width: $25 \mathrm{~ms}$.
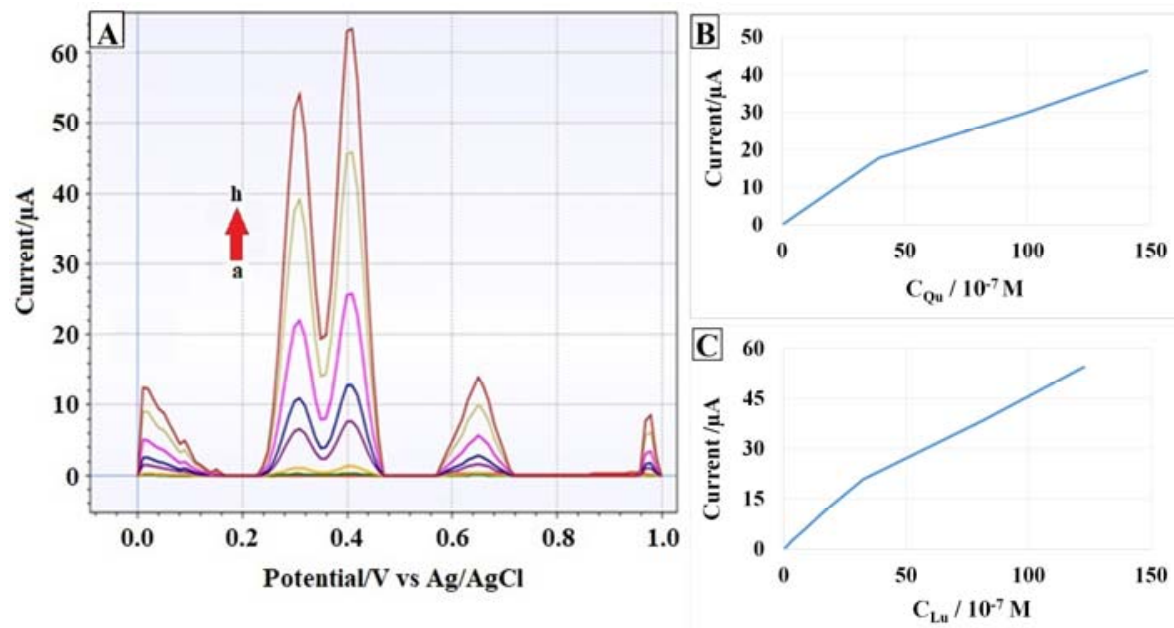

Fig. 7 - DPV curves of quercetin and luteolin at GCE in pH 5 phosphate buffer $(0.1 \mathrm{M}, 75 \%$ methanol), the concentrations of quercetin as follows (from a to h); $0.0792 \times 10^{-7}, 1.98 \times 10^{-7}, 3.96 \times 10^{-7}, 11.88 \times 10^{-7}, 19.80 \times 10^{-7}, 39.60 \times 10^{-7}, 99.00 \times 10^{-7}, 148$ $\times 50.10^{-7} \mathrm{M}$, and luteolin $0.0652 \times 10^{-7}, 1.63 \times 10^{-7}, 3.26 \times 10^{-7}, 9.78 \times 10^{-7}, 16.30 \times 10^{-7}, 32.60 \times 10^{-7}, 81.50 \times 10^{-7}, 122.50 \times 10^{-7} \mathrm{M}$ (A); The linear relationship between the peak currents and the quercetin (B) and luteolin (C) concentrations. Pulse amplitude: $50 \mathrm{mV}$, pulse width: $25 \mathrm{~ms}$. 
Table 2

Comparison of different researchers for $\mathrm{Qu}$ and $\mathrm{Lu}$ determination

\begin{tabular}{|c|c|c|c|c|c|c|c|}
\hline Electrode material & $\begin{array}{c}\text { Linear } \\
\text { Range for } \\
\mathbf{Q u} \\
\left(\times \mathbf{1 0}^{-7} \mathbf{M}\right) \\
\end{array}$ & $\begin{array}{c}\text { LOD for } \\
\text { Qu } \\
\left(\times 10^{-7}\right. \\
M)\end{array}$ & $\begin{array}{c}\text { Linear } \\
\text { Range for } \\
\text { Lu } \\
\left(\times \mathbf{1 0}^{-7} \mathrm{M}\right) \\
\end{array}$ & $\begin{array}{l}\text { LOD for } \\
\text { Lu } \\
\left(\times 10^{-7} \mathrm{M}\right)\end{array}$ & $\begin{array}{c}\text { Sensitivity } \\
\text { for } Q \mathbf{u} \\
(\boldsymbol{\mu} \mathbf{A} / \boldsymbol{\mu M} \times \\
\left.\mathbf{c m}^{2}\right)\end{array}$ & $\begin{array}{c}\text { Sensitivity } \\
\text { for } \mathbf{L u} \\
(\boldsymbol{\mu} \mathbf{A} / \boldsymbol{\mu} \mathbf{M} \times \\
\left.\mathbf{c m}^{2}\right)\end{array}$ & Reference \\
\hline $\begin{array}{c}\text { Pt- } \\
\text { PDA@SiO2/GCE }\end{array}$ & $0.5-3.83$ & 0.16 & - & - & 48.28 & - & 16 \\
\hline $\begin{array}{c}\text { MIP/MIL-101 } \\
\text { (Cr)/MoS } / \text { /GCE }\end{array}$ & $\begin{array}{l}1.0 \text { to } 105.0 \\
\text { and } \\
105.0 \text { to } \\
7000\end{array}$ & 0.6 & - & - & 1.90 & & 18 \\
\hline Pd/pGN-CNTs & $0.1-5.0$ & 0.050 & - & - & - & - & 20 \\
\hline GNs/HA/GCE & - & - & $\begin{array}{c}0.20 \text { to } \\
100.0\end{array}$ & 0.10 & - & 32.07 & 21 \\
\hline $\begin{array}{c}\text { Nbim/CNT- } \\
\text { modified glassy } \\
\text { carbon electrode }\end{array}$ & & & $0.05-3.2$ & 0.006 & - & - & 24 \\
\hline $\mathrm{MoS}_{2} / \mathrm{GN}-\mathrm{CNTs}$ & - & - & 0.40 to 20.0 & 0.090 & - & 381 & 25 \\
\hline GCE & $16.5-662$ & 16.5 & $8.7-419$ & 14.7 & - & - & 26 \\
\hline GCE & $\begin{array}{c}0.079-39.60 \\
\text { and } \\
39.60- \\
148.50\end{array}$ & 0.022 & $\begin{array}{c}0.065-32.60 \\
\text { and } \\
32.60- \\
122.50\end{array}$ & 0.018 & 63.71 & 91.00 & This work \\
\hline
\end{tabular}

Several modified electrodes were fabricated and successfully used for individual determination of $\mathrm{Qu}$ and $\mathrm{Lu}$, only one study reported simultaneous determination of $\mathrm{Qu}$ and $\mathrm{Lu}$. In the literature, individual or simultaneously determination of these molecules were carried out after some modification procedure or different calculation method (Table 2). ${ }^{16,18,20,21,24-26}$ In this study, the simultaneous determination of $\mathrm{Qu}$ and $\mathrm{Lu}$ was performed with high sensitivity and wide linear ranges using the unmodified GCE and calibration curve.

Under the optimum conditions, as an example of the analytical performance of the developed method for the simultaneous determination of $\mathrm{Qu}$ and $\mathrm{Lu}$, synthetic samples in different concentrations were analyzed by DPV. Linear response of the GCE was observed by studying the increment in the peak currents for the $\mathrm{Qu}$ and $\mathrm{Lu}$ in the concentration range $2.49-19.23 \times 10^{-7} \mathrm{M}$ (Figure 8A). Figures 8B and 8C show that the peak currents and the concentrations possessed a good linearity at the optimized conditions. The linear regression equations were:

$$
\text { Ip }=3.5541 \mathrm{C}+2.568\left(\mathrm{R}^{2}=0.9980\right) \text { for } \mathrm{Qu}
$$

and

$$
\text { I } p=5.8653 \mathrm{C}+0.2759\left(\mathrm{R}^{2}=0.9995\right) \text { for } \mathrm{Lu}
$$

The results were evaluated statistically (Table 3 ). The acceptable recoveries indicate the successful applicability of the developed method for simultaneous determination of $\mathrm{Qu}$ and $\mathrm{Lu}$.

In ethanol and methanol extracts of mate and white tea sample, standard addition method was used for the determination of $\mathrm{Qu}$ and $\mathrm{Lu}$. The results were listed in Table 4. For comparison, the $\mathrm{Qu}$ and $\mathrm{Lu}$ contents in extracts were also determined by HPLC (Table 4). The calculation of statistical evaluations showed good consonance between the mean values (t-test) and precision (F-test) for the two methods and the RSD values were less than $1 \%$. In other words, the results prove that the developed method is suitable for the 
simultaneous determination of $\mathrm{Qu}$ and $\mathrm{Lu}$ in real samples with high sensitivity and precision.

\section{Interference study}

For evaluating the selectivity of the development method, the influence of several interfering agents such as $\mathrm{Na}^{+}, \mathrm{K}^{+}, \mathrm{Cl}^{-}, \mathrm{NO}_{3}{ }^{-}, \mathrm{CO}_{3}{ }^{2-}$, glucose, fructose and sucrose and apigenin on the determinations of $\mathrm{Qu}$ and $\mathrm{Lu}$ at the optimal experimental conditions were investigated (each analyte $(\mathrm{Qu}$ and $\mathrm{Lu})$ concentration: $\left.1.92 \times 10^{-5} \mathrm{M}\right)$. The interference of these common inorganic ions and organic compounds were investigated for the electrochemical analysis of $\mathrm{Qu}$ and $\mathrm{Lu}$ in previous reports. ${ }^{16,20,24,32-34}$ The tolerance limit was calculated as the maximum concentration of the interfering agent which caused an approximately $\pm 5 \%$ decrease in the oxidation peak currents of $\mathrm{Qu}$ and $\mathrm{Lu}$ or shift in the oxidation potential of $\mathrm{Qu}$ and $\mathrm{Lu} . \mathrm{Na}^{+}, \mathrm{K}^{+}, \mathrm{Cl}^{-}, \mathrm{NO}_{3}^{-}, \mathrm{CO}_{3}{ }^{2-}$ did not significantly influence the height of the oxidation peak currents of $\mathrm{Qu}$ and $\mathrm{Lu} .150$ fold of sugars like glucose, fructose, and sucrose and, 10 fold of ascorbic acid did not affect the detections of $\mathrm{Qu}$ and $\mathrm{Lu}$. Besides, interference study was performed for the determinations of $\mathrm{Qu}$ and $\mathrm{Lu}$ in the presence of apigenin. Under the optimized conditions, the oxidation potential of apigenin was obtained at $0.920 \mathrm{~V}$, for this reason, apigenin had no interference effect.
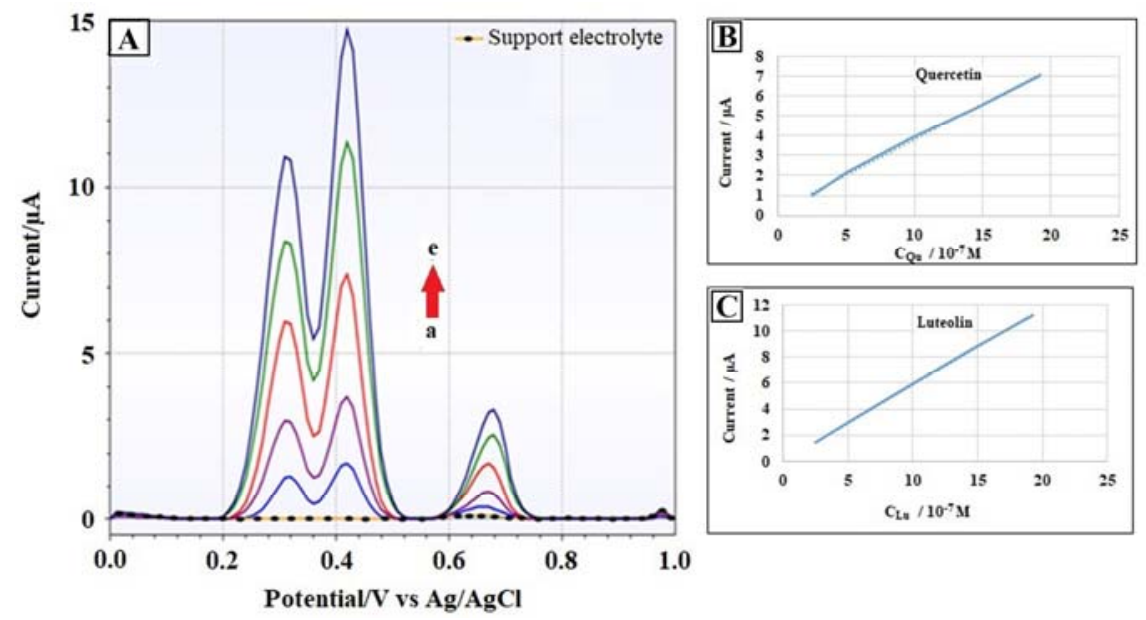

Fig. 8 - Differential puls voltammograms of quercetin and luteolin on GCE in pH 5 phosphate buffer $(0.1 \mathrm{M}, 75 \%$ methanol) (A); (B) and (C) plots of current versus concentration of $\mathrm{Qu}$ and $\mathrm{Lu}$. Concentration of each analyte (from a to e): $2.49 \times 10^{-7}, 4.95 \times 10^{-7}$, $9.80 \times 10^{-7}, 14.56 \times 10^{-7}, 19.23 \times 10^{-7}$ M. Pulse amplitude: $50 \mathrm{mV}$, pulse width: $25 \mathrm{~ms}$.

Table 3

The statistical evaluations of $\mathrm{Qu}$ and $\mathrm{Lu}$ at different concentrations

\begin{tabular}{|c|c|c|c|c|c|c|c|c|}
\hline \multirow[t]{2}{*}{ No } & \multicolumn{2}{|c|}{$\begin{array}{l}\text { Concentration of Added } \\
\qquad\left(\times 10^{-7} \mathrm{M}\right)\end{array}$} & \multicolumn{2}{|c|}{$\begin{array}{l}\text { Concentration of Found } \\
\qquad\left(\times 10^{-7} \mathrm{M}\right)\end{array}$} & \multicolumn{2}{|c|}{ Recovery \% } & \multicolumn{2}{|c|}{ RSD \% } \\
\hline & $\mathbf{Q u}$ & Lu & Qu & Lu & $\mathbf{Q u}$ & Lu & Qu & Lu \\
\hline 1 & 2.98 & 2.98 & $2.93 \pm 0.05$ & $2.95 \pm 0.02$ & 98.46 & 99.06 & 1.64 & 0.78 \\
\hline 2 & 2.98 & 5.93 & $2.94 \pm 0.07$ & $5.88 \pm 0.05$ & 98.79 & 99.09 & 2.31 & 0.89 \\
\hline 3 & 5.93 & 17.37 & $5.97 \pm 0.01$ & $17.26 \pm 0.02$ & 100.64 & 99.34 & 0.20 & 0.13 \\
\hline 4 & 5.93 & 2.98 & $5.99 \pm 0.01$ & $2.94 \pm 0.03$ & 101.05 & 98.66 & 0.13 & 1.06 \\
\hline 5 & 17.37 & 5.93 & $17.26 \pm 0.04$ & $5.88 \pm 0.01$ & 99.34 & 99.22 & 0.22 & 0.25 \\
\hline
\end{tabular}

$*_{\mathrm{n}}=5$ 
Table 4

Electrochemical determination results of $\mathrm{Qu}$ and $\mathrm{Lu}$ in ethanol and methanol extracts

\begin{tabular}{|c|c|c|c|c|c|c|c|c|c|c|c|c|}
\hline Sample & Extract & Analyte & $\begin{array}{l}\text { Detected } \\
\left(\times 10^{-7} \mathrm{M}\right)\end{array}$ & $\begin{array}{c}\text { Added } \\
\left(\times 10^{-7} \mathrm{M}\right)\end{array}$ & $\begin{array}{l}\text { Found* } \\
\left(\times 10^{-7} \mathrm{M}\right)\end{array}$ & RSD (\%) & $\begin{array}{l}\text { HPLC result* } \\
\quad\left(\times 10^{-7} \mathrm{M}\right)\end{array}$ & $\begin{array}{l}\text { RSD } \\
(\%)\end{array}$ & $\mathbf{F}_{\text {test }}$ & $\begin{array}{l}F_{\text {table }} \\
(\mathbf{9 5 \%})\end{array}$ & $t_{\text {test }}$ & $\begin{array}{c}\mathbf{t}_{\text {table }} \\
(95 \%)\end{array}$ \\
\hline \multirow{4}{*}{ Mate tea } & \multirow{2}{*}{ Ethanol } & $\mathrm{Qu}$ & 1.03 & 2.00 & 3.08 & 0.49 & 3.09 & 0.48 & 4.00 & 6.39 & 0.56 & 2.78 \\
\hline & & $\mathrm{Lu}$ & 0.88 & 2.00 & 2.92 & 0.48 & 2.92 & 0.43 & 5.06 & 6.39 & 0.00 & 2.78 \\
\hline & \multirow[b]{2}{*}{ Methanol } & $\mathrm{Qu}$ & 1.13 & 2.00 & 3.17 & 0.65 & 3.19 & 0.54 & 4.00 & 6.39 & 1.49 & 2.78 \\
\hline & & $\mathrm{Lu}$ & 0.94 & 2.00 & 2.97 & 0.62 & 2.98 & 0.54 & 2.97 & 6.39 & 0.75 & 2.78 \\
\hline \multirow{4}{*}{ White tea } & \multirow{2}{*}{ Ethanol } & $\mathrm{Qu}$ & 0.99 & 2.00 & 3.02 & 0.71 & 2.99 & 0.16 & 2.25 & 6.39 & 1.34 & 2.78 \\
\hline & & $\mathrm{Lu}$ & 0.86 & 2.00 & 2.83 & 0.62 & 2.87 & 0.62 & 5.44 & 6.39 & 1.28 & 2.78 \\
\hline & \multirow{2}{*}{ Methanol } & $\mathrm{Qu}$ & 1.01 & 2.00 & 3.03 & 0.64 & 3.01 & 0.64 & 1.44 & 6.39 & 0.75 & 2.78 \\
\hline & & $\mathrm{Lu}$ & 0.96 & 2.00 & 2.92 & 0.70 & 2.95 & 0.50 & 1.00 & 6.39 & 1.34 & 2.78 \\
\hline
\end{tabular}

$* \mathrm{x}=\overline{\mathrm{x}} \pm \mathrm{s}_{\mathrm{x}}$ for $\mathrm{n}=5, \mathrm{~s}_{\mathrm{x}}$ denotes standard deviation 


\section{EXPERIMENTAL}

\section{Materials and Methods}

\subsection{Chemicals}

Phosphate buffered saline (PBS) tablets were purchased from OXOID (Hampshire, England), quercetin and luteolin and all chemicals were purchased from Sigma-Aldrich (St. Louis, MO 63103 USA). All of them were used without further purification. Mate and white tea were purchased from a herbalist in Golbasi/Ankara. The support electrolyte, $\mathrm{pH} 5$ phosphate buffer $(0.1 \mathrm{M})$, was prepared using PBS tablet in methanol (75\%) and the $\mathrm{pH}$ was adjusted using $0.1 \mathrm{M} \mathrm{H}_{3} \mathrm{PO}_{4}$ and $0.1 \mathrm{M} \mathrm{NaOH}$. All chemicals were analytical grade. Double distilled water $(18.2 \mathrm{M} \Omega \mathrm{cm})$ was used in the preparation of each solution.

\subsection{Apparatus}

PalmSens3 Potentiostat/Galvanostat (PalmSens BV, Netherlands) was used for cyclic voltammetry (CV) and differential pulse voltammetry (DPV) measurements with a conventional three-electrode system, consisting of glassy carbon electrode (GCE) (BASi, MF-2012 (3.0 mm dia., West Lafayette, IN 47906 USA), $\mathrm{Ag} / \mathrm{AgCl}$ reference electrode (BASi, MF-2052, West Lafayette, IN 47906 USA) and platinum wire auxiliary electrode, was used. Agillent 1200 series HPLC system (Agilent Technologies, Inc., Santa Clara, CA 95051 United States) was also used for $\mathrm{Qu}$ and $\mathrm{Lu}$ chromatographic analysis. $\mathrm{Qu}$ and $\mathrm{Lu}$ were measured at room temperature on a column of ACE C18 $(250 \times 4.6 \mathrm{~mm})$ (Advanced Chromatography Technologies Ltd, Aberdeen, Scotland). The HPLC mobile phase consisted of water:methanol:acetic acid (75:20:5, v:v:v\%) (Solvent A) and water:methanol:acetic acid (50:45:5, v:v:v\%) (Solvent B). The gradient parameters were used as $0 \% \mathrm{~B}$ at $0 \mathrm{~min}, 100 \%$ at $30 \mathrm{~min}, 0 \%$ at $50 \mathrm{~min}$. The flow rate of $1.0 \mathrm{~mL} / \mathrm{min}$ was used throughout the experiment. The UV was also adjusted at $309 \mathrm{~nm}$ for detection. ${ }^{35}$ A bare GCE was mechanically polished with $0.3 \mu \mathrm{m}$ and $0.05 \mu \mathrm{m}$ alumina slurries on a microcloth pad. Polished GCE was sonicated in ultra-pure water and then with methanol for $10 \mathrm{~min}$. After these procedures, GCE was washed with ultra-pure water.

\subsection{Analytical procedure}

The necessary volume of standard or sample solution of $\mathrm{Qu}$ and $\mathrm{Lu}$ were pipetted to the electrochemical cell which was placed in $5 \mathrm{~mL}$ of $\mathrm{pH} 5$ phosphate buffer $(0.1 \mathrm{M}, 75 \%$ methanol). Then the CV and DPV oxidation peaks of Qu and $\mathrm{Lu}$ were recorded. The cyclic voltammetry was recorded from 0.0 to over the $1.0 \mathrm{~V}$ at a scan rate of $175 \mathrm{mV} / \mathrm{s}$ quiet time of $4 \mathrm{~s}$ and the DPV was recorded from 0.0 to $1.0 \mathrm{~V}$ with amplitude of $50 \mathrm{mV}$, quiet time of $4 \mathrm{~s}$ and pulse width of $25 \mathrm{~ms}$.

\subsection{Preparation of extracts}

Dried plant materials were powdered and were weighed thirty grams. $300 \mathrm{~mL}$ ethanol and methanol were used for extraction. Extraction was carried out with Soxhlet apparatus for $6 \mathrm{~h}$. The extract productions were concentrated under vacuum at $80{ }^{\circ} \mathrm{C}$ by using a rotary evaporator and before analysis; extracts in solvent were filtered with $0.20 \mu \mathrm{m}$ syringe filter and were stored in dark at $4{ }^{\circ} \mathrm{C} .{ }^{36}$

\section{CONCLUSIONS}

In this study, the overlapping of the oxidation peaks of $\mathrm{Qu}$ and $\mathrm{Lu}$ were shown and a method for their simultaneous determination was developed. For this purpose, optimized conditions such as chemical effects and the instrument parameter were investigated for obtaining the well-separation of peaks and better oxidation current values of $\mathrm{Qu}$ and $\mathrm{Lu}$. Methanol exhibited a significant effect for the separation of two analytes oxidation peaks on GCE. This simple and sensitive method was used for the determination of two species in real samples and voltammetric results were compared with HPLC results. Electrochemical and chromatographic results were in compliance. This method has some advantages such as short analysis time, small volume of sample and solvent, portable instrument, and cheap electrode.

Acknowledgements. This study was financially supported by the Gazi University, Projects of Scientific Investigation (No: 64/2017-01) and Gazi University, Life Sciences Research and Application Center.

\section{REFERENCES}

1. L. Kline and E. Karpinski, Nutr. Res., 2006, 36, 10981104.

2. M. Lesjak, I. Beara, N. Simin, D. Pintać, T. Majkić, K. Bekvalac, D. Orčić and N. Mimica-Dukić, J. Funct. Foods, 2018, 40, 68-75.

3. T. Funakoshi, N. Kanzaki, Y. Otsuka, T. Izumo, H. Shibata and S. Machida, Biochem. Biophys. Reports, 2018, 13, 39-44.

4. C. Zhang, R. Wang, G. Zhang and D. Gong, Int. J. Biol. Macromol., 2018, 112, 405-412.

5. C. Deng, C. Gao, X. Tian, B. Chao, F. Wang, Y. Zhang, J. Zou and D. Liu, J. Funct. Foods, 2017, 35, 332-340.

6. W. Fan, S. Qian, P. Qian and X. Li, Virus Res., 2016, 220, 112-116.

7. Y. Kwon, Exp. Gerontol., 2017, 95, 39-43.

8. F. Fang, J. M. Li, Q. H. Pan and W. D. Huang, Food Chem., 2007, 101, 428-433.

9. Z. Benmeddour, E. Mehinagic, D. Le Meurlay and H. Louaileche, J. Funct. Foods, 2013, 5, 346-354.

10. Q. Jin, J. Yang, L. Ma, D. Wen, F. Chen and J. Li, J. Food Compos. Anal., 2017, 63, 55-64.

11. I. M. Abu-Reidah, Á. Gil-Izquierdo, S. Medina and F. Ferreres, Food Res. Int., 2017, 100, 494-500.

12. T. Wang, J. Xiao, H. Hou, P. Li, Z. Yuan, H. Xu, R. Liu, Q. Li and K. Bi, J. Chromatogr. B, 2017, 1060, 173-181.

13. X. Dong, W. Lan, X. Yin, C. Yang, W. Wang and J. Ni, J. Evidence-Based Complementary Altern. Med., 2017, 2017, 1-7.

14. S. Şanlı, N. Şanli, S. A. Ozkan and C. Lunte, Chromatographia, 2016, 79, 1351-1358.

15. O. Monago-Maraña, A. Muñoz de la Peña and T. Galeano-Díaz, Talanta, 2016, 152, 15-22.

16. J. Manokaran, R. Muruganantham, A. Muthukrishnaraj and N. Balasubramanian, Electrochim. Acta, 2015, 168, 16-24.

17. A. T. E. Vilian, P. Puthiaraj, C. H. Kwak, S. R. Choe, Y. S. Huh, W. S. Ahn, Y and K. Han, Electrochim. Acta, 2016, 216, 181-187. 
18. W. Zhang, L. Zong, G. Geng, Y. Li and Y. Zhang, Sens. Actuators, B., 2018, 257, 1099-1109.

19. J. $\mathrm{Yu}, \mathrm{H}$. Jin, R. Gui, W. Lv and Z. Wang, J. Electroanal. Chem., 2017, 795, 97-102.

20. L. Yang, B. Xu, H. Ye, F. Zhao and B. Zeng, Sens. Actuators, B., 2017, 251, 601-608.

21. P. Pang, Y. Liu, Y. Zhang, Y. Gao and Q. Hu, Sens. Actuators, B., 2014, 194, 397-403.

22. A. Y. Tesio, A. M. Granero, N. R. Vettorazzi, N. F. Ferreyra, G. A. Rivas, H. Fernández and M. A. Zon, Microchem. J., 2014, 115, 100-105.

23. T. Wu, Z. Liu, Y. Guo, C. and Dong, J. Electroanal. Chem., 2015, 759, 137-143.

24. Y. Liao, N. Wang, Y. Ni, J. Xu and S. Shao, J. Electroanal. Chem., 2015, 754, 94-99.

25. B. Xu, B. Zhang, L. Yang, F. Zhao and B. Zeng, Electrochim. Acta, 2017, 258, 1413-1420.

26. F. Chamizo-Gonzalez, O. Monago-Marana and T. Galeano-Diaz, Electroanalysis, 2017, 29, 2757-2765.

27. R. Abdel-Hamid, M. K. Rabia and E. F. Newair, Arabian J. Chem., 2016, 9, 350-356.
28. A. K. Timbola, C. D. de Souza, C. Giacomelli and A. Spinelli, J. Braz. Chem. Soc., 2006, 17, 139-148.

29. A. Liu, S. Zhang, L. Huang, Y. Cao, H. Yao, W. Chen and X. Lin, Chem. Pharm. Bull., 2008, 56, 745-748.

30. A. Ghasemzadeh, H. Z. E. Jaafar and A. Rahmat, J. Med. Plants Res., 2011, 5, 1147-1154.

31. G. Bhattacharya, A. Mathur, S. Pal, J. McLaughlin and S. S. Roy, Int. J. Electrochem. Sci., 2016, 11, 6370-6386.

32. P. Xiao, F. Zhao and B. Zeng, Microchem. J., 2007, 85, 244-249.

33. D. Zhao, X. Zhang, L. Feng, Q. Qi and S. Wang, Food Chem., 2011, 127, 694-698.

34. S. Sadeghi and A. Garmroodi, Mater. Sci. Eng. C., 2013, 33, 4972-4977.

35. A. Ragusa, C. Centonze, M. E. Grasso, M. F. Latronico, P. F. Mastrangelo, F. Sparascio, F. P. Fanizzi and M. Maffia, Foods, 2017, 6, 1-10.

36. K. Karaboduk, O. Karabacak, H. Karaboduk and T. Tekinay, J. Environ. Prot. Ecol., 2014, 15, 1283-1292. 
